\title{
Culture, young people and wellbeing
}

Culture is the bedrock of nations. It is the collective manifestation of human intellectual achievement and will continue to determine societal responses to issues big and small. Our attitudes towards abuses of power, multilateralism and market failure are undoubtedly moulded through exposure to our cultural tapestry - literature, comedy, music and more. In this article I suggest that cultural consumption is a merit good and contend that the longstanding subsidisation of specific 'high arts' components of New Zealand's cultural sector is undesirable. Reorienting funding towards a 'cultural bonus' of $\$ 1,000$ for 18-year-olds would improve youth access to cultural goods and create a cultural sector more reflective of the desires of those who stand to shape our culture for an adult lifetime.

\section{Culture and wellbeing}

Individual studies (Grossi et al. 2012; Christin, 2011) and literature reviews (Ahuvia, 2002; Daykin et al., 2008; Bell, 2006) repeatedly demonstrate that participation in cultural activities has a strong correlation with improved wellbeing outcomes. The New Zealand Treasury's Living Standards Framework Dashboard confirms the significance of this causal link in a New Zealand context. Among younger New Zealanders (aged 15-34) a 'low' level of cultural identity correlates with a greater likelihood of poor/ low wellbeing across all the framework's 12 domains of wellbeing, while individuals with 'high' cultural identity are more likely to enjoy 'high' wellbeing in virtually all other domains (Treasury, 2020).

Interestingly, the framework illustrates that individuals aged between 15 and 34 with 'low' cultural identity have the strongest correlation with 'low' social connections of any domain. Further, 'low' cultural wellbeing has a stronger correlation

with 'low' health-related wellbeing than all other domains except for subjective wellbeing and civic engagement (ibid.). While the Dashboard is yet to incorporate a number of the recommendations put forward by a discussion paper jointly commissioned by the Treasury and Manatū Taonga, the Ministry for Culture and Heritage (Dalziel, Saunders and Savage, 2019), this data clearly illustrates the importance of cultural participation and identity among young New Zealanders.

\section{Equity and choice}

While current subsidisation of cultural consumption is significant, only a small number of organisations receive the bulk of total funding. In 2019 the Ministry for Culture and Heritage contributed an additional $\$ 14,646$ million to the New Zealand Symphony Orchestra, \$5,384 million to the Royal New Zealand Ballet, $\$ 15,689$ million to Creative New Zealand, and $\$ 146,766$ million to NZ On Air (Ministry for Culture and Heritage, 2019, p.81). Government funding comprises $73 \%$ of the income of the New Zealand Symphony Orchestra and represents a subsidy of over $\$ 128.80$ per attendance (New Zealand Symphony Orchestra, 2019, p. 21 ), and $42 \%$ of total turnover for the Royal New Zealand Ballet, representing a subsidy of over $\$ 73$ per attendance (Royal New Zealand Ballet, 2019, p.3).

Despite this significant subsidisation, more than $62 \%$ of New Zealanders surveyed by Creative New Zealand in 2017

Hugo Thompson is a Master of Public Policy student in the School of Government at Victoria University of Wellington. agreed with the statement that, 'while some arts events interest me I still don't go much'. Furthermore, a significant minority (21\%) of young people agreed that they would participate more if arts activities were cheaper or free, or if more and better activities were happening where they lived' (Creative New Zealand, 2017, pp.5-6). This is worrying. Despite subsidisation, many New Zealanders - and particularly youth - are not consuming cultural goods at a rate that they deem desirable from an individual, short-term utility maximisation perspective, let alone at a rate that is reflective of positive associated externalities.

I suggest that this mismatch between the changing desires of younger people and where funding is targeted is indicative of a first-mover advantage. Existing 'high culture' institutions remain dominant and receive a significant allocation of central government cultural spending, while also benefiting from voluntary price discrimination (donations) from their established base of patrons. In contrast, the emerging cultural interests of young people are not catered for to the same extent.

\section{Market failure}

Clearly, cultural consumption is a merit good: participation/consumption by individuals benefits those who participate and results in positive externalities benefiting society at large. Self-interested, possibly myopic, consumers are personal (and often short-term) utility maximisers who do not consume these cultural goods at the desired level.

Like the old parable of a lighthouse, where those not willing or able to pay for its upkeep enjoy its navigational benefits without compromising its use by others, a strong national culture is a non-rivalrous and non-excludable product. While this then appears to meet the definition of a public good, and justify public funding 
through government, we must highlight the excludable products that develop and sustain this good. Performances, sports club memberships and access to copyrighted works are tangible examples of club goods (non-rivalrous but excludable goods) that sustain and further our cultural health.
2015 Paris terror attacks, the Italian government of Matteo Renzi announced a package of more than $€ 1$ billion for defence, as well as an entirely unexpected programme - Bonus Cultura - whereby every Italian citizen and resident would be gifted $€ 500$ in the year of their 18th birthday to spend

\section{The [New Zealand] government's RealMe platform provides an intermediary digital identification service similar to the SPID offering from Italy's Agenzia per l'Italia digitale.}

Naturally, where club goods have a low rivalry of consumption, the costs associated with providing the good to each additional consumer represent a small portion of total costs. Hansmann (1981) suggests that the predominance of non-profit organisations in the performing arts is likely a result of market failure stemming from these high average, and low marginal, costs. He also makes the claim that because charging above average costs would result in poor patronage from consumers with a high elasticity of demand, charging below average cost and encouraging donations with a non-profit status both maximises consumer surplus and allows for voluntary price discrimination. In effect, this phenomenon allows non-profits to remain financially viable where businesses reliant on charging above average costs could not compete.

I suggest that young people are particularly disadvantaged by this market outcome. While large numbers of youth may desire access to a specific club good, a relative lack of discretionary income reduces the ability of youth to voluntarily price discriminate. This reduces the viability of charging below average costs for the whole cohort, ultimately resulting in low consumption, high average costs and reduced consumer surplus.

\section{The Italian model}

Italy has been a pioneer in boosting the cultural spending power of youth and has enjoyed a partial cultural renaissance as a result. Within a fortnight of the November
The French have adopted a similar system to 'Bonus Cultura', and have rebranded the policy instrument as a 'Culture Pass', with nationwide coverage planned for 2020. Similarly, 18-year-olds can access the same $€ 500$, but they are restricted to a limit of $€ 200$ on material purchases such as books, videos and music (Aide-sociale, n.d).

\section{A Kiwi cultural bonus}

The New Zealand government has both the infrastructure and mandate to enact a similar policy programme for $\mathrm{New}$ Zealand's youth. The government's RealMe platform provides an intermediary digital identification service similar to the SPID offering from Italy's Agenzia per l'Italia digitale. Further, with an estimated resident population of 18 -year-olds in New Zealand of 62,840 (Statistics New Zealand, 2020), and assuming a maximum spend of $\$ 1,000$ for each individual, the administration-exclusive cost would not exceed NZ\$65 million on an annual basis.

If this proposal were to be seriously considered, engaging a representative sample of New Zealanders through a survey, with a focus on young adults, to test their support for the proposal would be a critical next step. Using this survey data to determine the likely areas of the cultural sector that would benefit most from this potential spending would allow policy analysts to determine the likelihood of this intervention addressing the existing market failures affecting the cultural sector, through a forecast reduction in average costs via increased participation.

While some may claim that a policy of financial transfers in the context of cultural consumption risks monetising how individuals perceive and engage with culture, both the market and current government subsidisation for culture have failed to adapt to change. Evidence continues to mount that illustrates the role of a healthy cultural sector in improving individual (and by extension societal) wellbeing.

While institutions such as the Royal New Zealand Ballet have proven themselves valuable pieces of New Zealand's cultural landscape, we must question if the sums currently used to keep these otherwise unsustainable operations afloat would be better placed in the hands of those who otherwise lack access and who stand to shape our cultural landscape for an adult lifetime. 


\section{References}

Ahuvia, A.C. (2002) 'Individualism/collectivism and cultures of happiness: a theoretical conjecture on the relationship between consumption, culture and subjective well-being at the national level', Journal of Happiness Studies, 3, pp.23-36

Aide-Sociale (2020) 'What is the culture pass about? Who is it for and when can young people benefit from the 500 euros?', https://www. aide-sociale.fr/pass-culture/\#qui

Bell, D. (2006) 'Review of research into subjective wellbeing and its relation to sport and culture' in Scottish Executive (ed.), Quality of Life and Wellbeing: measuring the benefits of culture and sport: literature review and think piece, Annex 1, Edinburgh: Scottish Executive

Christin, A. (2011) Gender, Early Socialization in the Arts and Cultural Participation in the United States, CACPS working paper 42, Princeton: Princeton University

Creative New Zealand (2017) New Zealanders and the Arts, https://www. creativenz.govt.nz/assets/paperclip/publication_documents/ documents/606/original/new-zealanders-and-the-arts-summary-report. pdf?1526981303

Dalziel, P., C. Saunders and C. Savage (2019) Culture, Wellbeing, and the Living Standards Framework: a perspective, discussion paper 19/02, prepared for the Ministry for Culture and Heritage and Treasury

Daykin, N., J. Orme, D. Evans, D. Salmon, M. McEachran and S. Brain (2008) 'The impact of participation in performing arts on adolescent health and behavior: a systematic review of the literature', Journal of Health Psychology, 13, pp.251-64

Grossi, E., A. Compare, C. Lonardi, R. Cerutti, E. Callus and M. Niero (2012) 'Gender-related effect of cultural participation in psychological well-being: indications from the well-being project in the municipality of Milan', Social Indicators Research, 114 (2)

Hansmann, H. (1981) 'Nonprofit enterprise in the performing arts', Bell Journal of Economics, 12 (2), pp.341-61

II Post (2018) 'Come è stato usato il "bonus cultura" per i 18enni', I/ Post Libri, 20 June, https://www.ilpost.it/2018/06/20/bonus-culturaeditoria-italiana/

Ministry for Culture and Heritage (2019) Annual Report 2019, https://mch. govt.nz/sites/default/files/projects/Annual\%20Report\%202018-19.pdf

New Zealand Symphonic Orchestra (2019) Annual Report 2018, https:// www.nzso.co.nz/assets/Uploads/downloads/NZSO-AnnualReport-2018.pdf

Observatory of Public Sector Innovation (2018) 'Bonus Cultura - 18app', https://oecd-opsi.org/innovations/bonus-cultura-18app/

Royal New Zealand Ballet (2019) Annual Report 2018, http://rnzb.org.nz/ wp-content/uploads/2019/05/RNZB-Annual-Report-2018-_018.pdf

Statistics New Zealand (2020) 'Table: estimated resident population by age and sex $(1991+)($ Qrtly-Mar/Jun/Sep/Dec)', 18 February, http:// archive.stats.govt.nz/infoshare/ViewTable.aspx?pxID=ce82d62a-d5844b4c-aefe-0a9324daabea

Squires, N. (2016) "Italian teenagers to receive $€ 500$ "cultural bonus" from government', Telegraph, 26 August, https://www.telegraph.co.uk/ news/2016/08/23/italian-teenagers-to-receive-500-cultural-bonusfrom-government/

Treasury (2020) 'Living Standards Framework - Dashboard: Our people: relationships between LSF domains', https://sfdashboard.treasury.govt. nz/wellbeing/\#shiny-tab-op introduction

UNESCO. (n.d.). 'World heritage list', https://whc.unesco.org/en/list 